\title{
HUBUNGAN BMI DENGAN KADAR KOLESTEROL TOTAL DARAH PADA WANITA DEWASA
}

\author{
Radot Ganda Sinurat ${ }^{*}$, Yunus Elon ${ }^{2}$ \\ ${ }^{1,2}$ Fakultas Ilmu Keperawatan, Universitas Advent Indonesia \\ "E-mail: sinuratr22_growed@yahoo.com
}

\begin{abstract}
Hypercholesterolemia is a state of high total cholesterol levels in the body, which is a significant risk factor for cardiovascular disease which is still the number one cause of death in the world with the same prevalence between men and women. This study aims to determine the relationship of Body Mass Index (BMI) with total cholesterol levels in blood in adult women in Cihanjuang Rahayu Village.

This study uses a cross sectional analytic observational design. The number of samples in this study were 45 respondens. As many as 19 or $42 \%$ of respondent fall into the fat category, $31 \%$ or 14 obese respondents, and $27 \%$ are normal. Total cholesterol $76 \%$ or as many as 34 normal respondents , and 24 $\%$ or 11 people with hypercholesterolemia. The analysis showed that there was no significant relationship between BMI and cholesterol levels in adult women with p-values. >.05. Conclution: the adult women aged $26-45$ years BMI status is not related to total cholesterol levels.
\end{abstract}

Key words: Total Cholesterol, Hypercholesterolemia, Body Mass Index

\begin{abstract}
Abstrak
Hiperkolesterolemia adalah keadaan kadar kolesterol total tinggi di dalam tubuh, yang merupakan faktor resiko signifikan dari penyakit kardiovaskular yang sampai pada saat ini masih menjadi penyebab nomor satu kematian di dunia dengan prevalensi yang sama antara pria dan wanita. Penelitian ini bertujuan untuk mengetahui adanya hubungan Body Mass Index (BMI) dengan kadar kolesterol total dalam darah pada wanita dewasa di Desa Cihanjuang Rahayu. Penelitian ini menggunakan desain cross sectional yang bersifat analitik observational. Jumlah sampel pada penelitian ini sebanyak 45 responden. Sebanyak 19 atau $42 \%$ responden masuk dalam kategori gemuk, $31 \%$ atau 14 responden obesitas dan $27 \%$ Normal. Total kolesterol $76 \%$ atau 34 responden normal, dan $24 \%$ atau 11 orang hyperkolesterolemia. Hasil analisis menunjukkan tidak ada hubungan yang signifikan antara BMI dengan kadar total kolesterol pada wanita dewasa dengan nilai p-value $>.05$. Kesimpulan: pada wanita dewasa usia 26 tahun -45 tahun status BMI tidak berhubungan dengan kadar kolesterol total.
\end{abstract}

\section{Kata kunci: Kolesterol Total, Hiperkolesterolemia, Indeks Massa Tubuh}

\section{Pendahuluan}

Peningkatan kadar kolesterol dalam tubuh, dapat berakibat serius terhadap status kesehatan individu. Seseorang yang memiliki kadar kolesterol dalam darah diatas 200mg/dl memiliki resiko tinggi terhadap penyakit jantung dan pembuluh darah (Griffin, 2014; Nelson, 2013).
Menurut World Health Organization (WHO), (2014) sebanyak $37 \%$ kematian di Indonesia disebabkan oleh penyakit jantung dan pembuluh darah. Dimana $35.9 \%$ usia 15 tahun keatas memiliki kadar kolesterol >200 mg/dL. Jika tidak dilakukan penanganan yang serius seseorang dengan 
hyperkolesterolemia akan mengalami komplikasi berupa penyakit kardiovaskular yang merupakan pembunuh nomor 1 didunia (Elon, Polancos, 2015).

Gostynski (2004) terdapat consensus bahwa kadar kolesterol total meningkat sehubungan dengan peningkatan Body Mass Index. Pravelensi peningkatan total kolesterol tertinggi adalah Wilayah Eropa (54\% untuk kedua jenis kelamin) diikuti oleh wilayah Amerika (48\% untuk kedua jenis kelamin) (World Health Organization, 2008). Sedangkan Linawati, (2011) menyatakan wanita menjadi kelompok paling banyak menderita masalah ini yakni 14,5\% atau hampir dua kali lipat kelompok laki-laki.

Perubahan pola hidup masyarakat yang serba modern dan praktis terutama wanita yang sudah dewasa sebagian besar enggan tidak melakukan pola hidup sehat. Dampak dari pola hidup yang tidak sehat mengakibatkan rasio antara tinggi dan berat badan tidak ideal atau yang kita kenal dengan body mass index (BMI). Pola hidup tidak sehat dan aktivitas fisik yang kurang, sehingga beresiko mengalami obesitas. Obesitas adalah kondisi kelebihan berat tubuh akibat tertimbunnya lemak, untuk pria dan wanita masing-masing melebihi $20 \%$ dan $25 \%$ dari berat tubuh (Siagian , 2004). Saat ini, body mass index (BMI) merupakan salah satu parameter yang dapat digunakan dalam menentukan kriteria proporsi tubuh seseorang.

Menurut Riset Kesehatan Dasar (Riskesdas) 2013 pada kelompok laki-laki dewasa pravelensi obesitas pada tahun 2013 meningkat 11,9\% dari tahun 2010, sedangkan pravelensi obesitas pada kelompok perempuan dewasa meningkat 17,5\% di tahun 2010 . Berat badan berbanding lurus dengan jumlah lemak dalam darah, seseorang dengan berat badan yang berlebih memiliki risiko tinggi meningkatnya jumlah lemak dalam darah. Masalah kelebihan berat badan ini merupakan masalah yang dapat dicegah. Jika masalah ini dapat dikendalikan maka akan menurunkan risiko hipertensi, PJK dan stroke.

Menurut Rachmi, et al, (2017) Faktor- faktor yang dapat menyebabkan obesitas dan overweight antaralain status sosial dan ekonomi, daerah tempat tinggal, gaya hidup yang buruk, dan faktor nutrisi makanan seseorang. (Rachmi et al, 2017).

Penelitian ini bertujuan untuk mengetahui gambaran rata-rata BMI, kolesterol total darah serta hubungan body mass index dengan kadar kolesterol total pada wanita dewasa.

\section{Bahan dan Metode}

Penelitian ini menggunakan desain cross sectional yang bersifat observasional analitik, karena ingin menganalisis hubungan antar variabel. Populasi responden pada penelitian ini adalah seluruh wanita dewasa di RW 12 desa cihanjuang rahayu. Untuk menentukan populasi penelitian dan sampel penelitian terdapat kriteria inklusi dan ekslusi. Kriteria inklusi yang diterapkan adalah: wanita dewasa usia 26 - 45 tahun, sehat jasmani serta tidak sedang hamil dan menyusui. Sedangkan kriteria ekslusi adalah: wanita dewasa yang sudah pernah memeriksakan kolesterol total dan di diagnosa memiliki kolesterol total yang tinggi yaitu $>200$. Dari total populasi wanita dewasa yang memenuhi kriteria inklusi diambil sampel dengan menggunakan rumus Slovin, didapatkan jumlah sampel sebanyak 45 responden.

$$
n=\frac{\mathrm{N}}{1+\mathrm{N} e^{2}}
$$

Keterangan:

(n) = Ukuran Sampel

$(\mathrm{N})=$ Ukuran Populasi 
(e) $=$ Taraf kesalahan (error) sebesar 0,10 (10\%)

Sebelumnya penelitian ini mendapat keterangan layak etik No.020/KEPK-FIK.UNAI/EC/VIII/19. Adapun proses pengambilan sampel dilakukan dengan mendatangi calon respoden ke rumah masing-masing calon responden, apabila sesuai dengan kriteria maka peneliti akan menjelaskan tujuan penelitian dan jika responden bersedia maka peneliti memberikan informed consent kepada responden. Saat responden memberikan pertanyaan, peneliti memberikan penjelasan sebelum responden menandatangani informed consent. Yang bersedia diminta untuk berpuasa selama 10 jam dimulai dari pukul 22 malam sampai pukul 8 pagi. Keesokan harinya, sebelum pengambilan darah oleh petugas laboratorium, peneliti mengukur tinggi badan dengan menggunakan stature meter dan selanjutnya mengukur berat badan dengan timbangan digital yang terkalibrasi. Hasil perhitungan antara tinggi badan dan berat badan diklasifikasikan berdasarkan kategori BMI.

Tabel 1. Kategori Body Mass Index (BMI)

\begin{tabular}{cc}
\hline Kategori & Rentang \\
\hline Underweight & $<18,5$ \\
Normal & $25-29,5,9$ \\
Overweight & $\geq 30$ \\
Obesitas &
\end{tabular}

World Health Organization, 2016

Tempat pengambilan sampel dilakukan di aula SMK Perjuangan-Parompong oleh petugas Lab. Rumah Sakit Jiwa-Cisarua. Selanjutnya petugas akan mengambil darah dengan menggunakan vacuum spuit $\div 3 \mathrm{cc}$ yang akan dianalisis menggunakan mesin cobas integra yang telah dikalibrasi.
Kemudian hassil akan dinterperatasikan dengan menggunakan standard pada tabel 2

Tabel 2. Kategori Kadar Kolesterol Total

\begin{tabular}{clc}
\hline Kadar & Rentang & Kategori \\
\hline $\begin{array}{c}\text { Kolesterol } \\
\text { Total }\end{array}$ & $<200 \mathrm{mg}$ & Normal \\
& $200-239$ & Borderline \\
& $\mathrm{mg} / \mathrm{dL}$ & \\
& $\geq 240 \mathrm{mg}$ & Tinggi \\
& $/ d L$ & \\
\hline
\end{tabular}

National Institutes of Health, 2002.

Data dianalisis menggunakan perangkat software SPSS. Analisis Univariate digunakann untuk analisa data demografi, dan Analisis Bivariate digunakan untuk melihat hubungan antara BMI dengan total kolesterol. Hasil analisis menunjukkan data berdistribusi normal dengan menggunakan Kolmogorov-Smirnov (Sig = .200) sehiingga uji korelasi menggunakan Pearson Product-Moment Correlation.

\section{Hasil dan Pembahasan}

Penelitian ini dilakukan pada bulan September 2019 terhadap 45 wanita dewasa muda, adapun karakteristik subyek berdasarkan usia, status, pendidikan, BMI dan kadar kolesterol total akan disajikan dalam bentuk tabel dan gambar dibawah Tabel 3. Karakteristik Subyek Menurut Usia 
Sumber: Data primer

Berdasarkan data pada tabel menunjukkan responden sebanyak 45 dengan rentang persentasi usia 26 - 30 tahun 9 orang (20\%), usia 31 -35 tahun sebanyak 12 orang (27\%), usia 36 - 40 tahun sebanyak 15 orang (33\%), usia 41 - 45 tahun sebanyak 9 orang $(20 \%)$. Usia yang semakin dewasa dapat meningkatkan kandungan lemak tubuh, terutama pada lemak perut. Semakin bertambah usia maka kadar kolesterol total relative lebih tinggi dari pada usia muda. Perubahan hormon memicu penumpukan lemak viseral. Perempuan mengontrol kelebihan energi sebagai lemak simpanan (Pradana Adhitya, 2010).

Hormon estrogen berperan dalam menyeimbangkan kadar kolesterol tubuh dengan mekanisme membatasi asam lemak bebas masuk kembali ke hati. Hati berperan dalam mengoksidasi kembali asam lemak bebas, dapat menyebakan akumulasi diacylglycerol dan kemudian akan mengakibatkan peningkatan LDL dalam tubuh.

(Palmisano et al, 2017).

Tabel 4. Karakteristik Subyek Menurut Status Pernikahan

\begin{tabular}{ccc}
\hline $\begin{array}{c}\text { Status } \\
\text { Pernikahan }\end{array}$ & $\mathbf{n}$ & $\mathbf{( \% )}$ \\
\hline Menikah & 34 & $76 \%$ \\
Janda & 9 & $20 \%$ \\
Cerai & 2 & $4 \%$ \\
\hline Jumlah & 45 & $100 \%$
\end{tabular}

\section{Sumber: Data primer}

Berdasarkan data tabel diatas menunjukkan dari 45 responden diketahui bahwa sebanyak 34 orang sudah menikah (76\%), sebanyak 9 orang janda $(20 \%)$ dan sebanyak 2 orang telah bercerai (4\%).
Dari data diatas dapat disimpulkan bahwa rata-rata

\begin{tabular}{ccc}
\hline Usia & $\mathbf{n}$ & $\mathbf{( \% )}$ \\
\hline $26-30$ tahun & 9 & $20 \%$ \\
$31-35$ tahun & 12 & $27 \%$ \\
$36-40$ tahun & 15 & $33 \%$ \\
$41-45$ tahun & 9 & $20 \%$ \\
\hline Jumlah & 45 & $100 \%$ \\
\hline
\end{tabular}

wanita sudah menikah. Pernikahan adalah sebuah gerbang untuk membentuk keluarga yang bahagia. Pernikahan itu sendiri adalah suatu hal yang sangat dianjurkan. Menurut Walgito (2000), suami istri perlu saling membantu dan melengkapi agar masing-masing dapat mengembangkan kepribadiannya mencapai kesejahteraan spiritual dan kesehatan yang optimal. Zheng (2013) dari University of Texas di Austin mengutip "Pernikahan sangat membantu dalam membujuk orang untuk mengadopsi gaya hidup sehat yang dapat memperpanjang hidupnya. Ellen Idler, sosiolog dari University Emory mengatakan orang dewasa yang menikah mampu bertahan hidup lebih lama dibandingkan orang yang belum menikah, yang sudah cerai dan berpisah.

Tabel 5. Karakteristik Subyek Menurut Pendidikan

\begin{tabular}{ccc}
\hline Pendidikan & n & $(\boldsymbol{\%})$ \\
\hline SD & 20 & $45 \%$ \\
SMP & 20 & $44 \%$ \\
SMA & 5 & $11 \%$ \\
\hline Jumlah & 45 & $100 \%$ \\
\hline
\end{tabular}

Sumber: Data primer

Beradasarkan data pada tabel diatas menunjukkan dari 45 orang responden, sebanyak 20 orang dengan pendidikan terakhir SD (45\%), 20 orang dengan 
pendidikan terakhir SMP (44 \%) dan 5 orang dengan pendidikan terakhir SMA (11 \%). Pendidikan adalah suatu usaha manusia untuk meningkatkan kepribadian dan proses perubahan perilaku menuju kedewasaan dan penyempurnaan kehidupan dengan membina dan mengembangkan potensi kepribadiannya. Seseorang yang memiliki pendidikan yang tinggi, akan terpapar pengetahuan dan kesadaran tentang kesehatan. Menurut Niven (2008) Perilaku kesehatan adalah perilaku yang harus dilakukan seorang untuk cara pengobatan atau nasehat yang ditentukan oleh tenaga kesehatan yang dapat memperbaiki keadaan dan kondisi kesehatan.

Menurut Kozier et al (2011) dan Notoatmojo (2012) faktor-faktor yang mempengaruhi kepatuhan yaitu motivasi, pengetahuan, sikap, dan nilai, kepercayaan serta faktor eknomi. Semakin tinggi status pendidikan seseorang dapat menekan resiko terserang penyakit dan meningkatkan kesehatan yang optimal.

Tabel 6. Karakteristik Subyek Menurut Kategori BMI

\begin{tabular}{ccc}
\hline $\begin{array}{c}\text { Kategori } \\
\text { BMI }\end{array}$ & $\mathbf{n}$ & $\mathbf{( \% )}$ \\
\hline Normal & 12 & $27 \%$ \\
Gemuk & 19 & $42, \%$ \\
Obesitas & 14 & $31 \%$ \\
\hline
\end{tabular}

Tabel 7. Karakteristik Subyek Menurut kategori Kolestrol Total

\section{Kategori}

$\mathbf{n}$

(\%)

\section{Kolesterol Total}

$<200 \mathrm{mg} / \mathrm{dL}$

$34 \quad 76 \%$
Jumlah
45
$100 \%$

\section{Sumber: Data primer}

\section{Body Mass Index (BMI)}

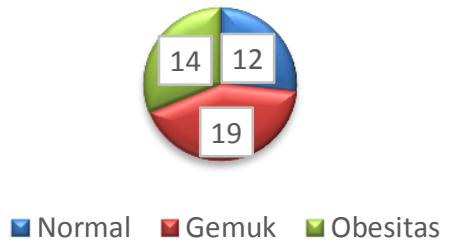

Gambar 1. Pengelompokan BMI subyek menurut WHO, 2016

Berdasarkan data pada tabel diatas menunjukkan dari 45 orang responden, sebanyak 12 orang berkategori berat badan normal (27\%), sebanyak 19 orang masuk kategori gemuk atau overweight (42 $\%$ ) dan sebanyak 14 orang masuk kategori obesitas (31 \%). Meningkatnya indeks massa tubuh (overweight atau obese) atau disebut adiposity disebabkan oleh meningkatnya akumulasi lemak. Schaefer, (2010) Produksi kolesterol dalam tubuh akan meningkat pada orang yan mengalami obesitas dan metabolic syndrome. Ketika body mass index (BMI) seseorang tinggi, maka akan terjadi peningkatan kadar asam bebas, menyebabkan adanya pelepasan asam bebas dalam jumlah besar dalam darah dan dapat mengindikasikan peningkatan kolesterol darah (Musdalifa et al, 2017).

\section{Kolesterol Total}

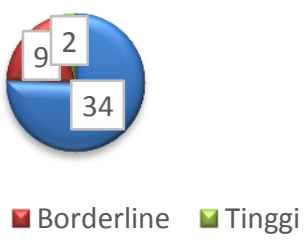




\begin{tabular}{ccc}
$200-239 \mathrm{mg} / \mathrm{dL}$ & 9 & $20 \%$ \\
$\geq 240 \mathrm{mg} / \mathrm{dL}$ & 2 & $4 \%$ \\
\hline Jumlah & 45 & $100 \%$
\end{tabular}

Sumber: Data prime

Gambar 2. Pengelompokan kadar Kolesterol Total Subyek menurut Nasional Institutes of Health, 2002

Berdasarkan data dari tabel diatas menunjukkan dari 45 orang responden, sebanyak 34 orang masuk kategori kolesterol total normal (76\%), sebanyak 9 orang masuk kategori kolesterol total Borderline (20\%) dan sebanyak 2 orang masuk kategori kolesterol total tinggi (4\%). Dari statistik diatas dapat ditarik kesimpulan bahwa rata-rata kolesterol total pada wanita dewasa di RW 12 dalam batas normal. Kolesterol dalam tubuh dipengaruhi oleh faktor pola konsumsi makanan. Pola konsumsi makanan yang banyak mengandung lemak jenuh seperti daging, kuning telur, produk dari tumbutumbuhan tertentu (minyak kelapa) dapat meningkatkan kadar kolesterol dalam darah (Lombo et al, 2012). Menurut AHA, (2016) Wanita usia subur cenderung memiliki kadar kolesterol lebih rendah dibandingkan dengan pria. Ketika wanita memasuki usia monopause kadar kolesterol cenderung mengalami peningkatan. Peneliti mendapatkan bahwa wanita yang menjadi responden berusia 26-45 tahun, setiap harinya sebagian besar wanita disana berprofesi sebagai petani sehingga mereka harus bekerja sepanjang hari berangkat pagi dan pulang pada sore hari. Oleh karena itu peneliti berpendapat sehingga tidak ada hubungan yang signifikan antara BMI dengan kadar kolesterol total dalam darah.

\section{Kesimpulan}

Pada penelitian ini dapat disimpulkan bahwa tidak ada hubungan yang bermakna antara BMI dengan kadar kolesterol total $(\mathrm{p}=$.928) pada wanita dewasa di RW 12 Desa Cihanjuang Rahayu.

\section{Saran}

Berdasarkan hasil penelitian yang diperoleh, peneliti memberikan saran untuk penambahan jumlah responden dalam mewakili populasi, mengalami obesitas dan dilakukan pada daerah lain.

Tabel 8. Hubungan BMI dengan Kadar Kolesterol Total Pada Wanita Dewasa

\begin{tabular}{ccccc}
\hline & & & Koefisien & Sig. \\
Variabel & Mean & Std. Deviation & Korelasi & (2-tailed) \\
\hline
\end{tabular}

Body Mass Index (BMI)

28.4547

Kolesterol
182.6889
4.57632

28.50504
.014 
Total

Significant at $\alpha=<.005$

Penelitian ini dilakukan pada seluruh wanita dewasa usia 26-45 tahun, dimana pada usia tersebut hormon estrogen pada wanita masih di produksi secara aktif. Estrogen merupakan hormone yang bertanggung jawab terhadap peningkatan konsentrasi HDL, Penurunan LDL dan Lipoprotein. Peran estrogen dalam meningkatkan HDL dan menurunkan LDL hampir mencapai $15 \%$.

Berdasarkan hasil penelitian menunjukkan p-value .928 ( $p>0,05)$ berarti, tidak terdapat perbedaan yang signifikan antara hubungan BMI dengan kadar kolesterol total pada wanita dewasa di cihanjuang rahayu. Penelitian ini sesuai dengan yang dikemukakan Sitepu W. Indah (2014) tidak terdapat hubungan yang bermakna antara Indeks Massa Tubuh (BMI) dengan Kadar Kolesterol Total.

Penelitian yang sama Nugraha Aziz (2014) mengatakan tidak terdapat hubungan yang signifikan antara indeks massa tubuh dengan kadar kolesterol total. Kolesterol yang tinggi tidak selalu dipengaruhi oleh obesitas tetapi lebih pada kebiasaan mengkonsumsi makanan yang banyak mengandung tinggi kolesterol. Disamping dipegaruhi oleh data demografi seperti : usia, status pernikahan, pendidikan, body mass index terdapat juga faktor lain yaitu aktivitas sehari hari. Wanita dewasa yang ikut dalam penelitian ini ialah sebagian mayoritas pekerjaannya berkebun dan bercocok tanam. Hal ini menjadi salah satu faktor yang menyebakan tidak ada hubungan yang berarti antara BMI dengan kadar kolesterol total. Seorang petani akan bekerja sepanjang hari sehingga diperlukan energi yang cukup besar. Kolesterol akan dipecah dan diproses menjadi sumber energi oleh tubuh. Kolesterol merupakan zat yang dibutuhkan oleh tubuh dan memiliki fungsi membantu seluruh proses enzimatis dalam tubuh. Aktivitas yang dilakukan dapat mempengaruhi kadar kolesterol dalam darah. Mujur, (2011) aktivitas fisik merupakan faktor resiko dari kejadian overweight, seseorang yang beraktivitas ringan berhubungan erat dengan berat badan berlebih. Oleh sebab itu, untuk mencegah kelebihan berat badan dan obesitas perlu dilakukan aktivitas fisik yang sesuai, aman dan efektif dalam upaya menurunkan berat badan. Penelitian dengan judul hubungan antara konsumsi pangan dan aktivitas fisik dengan kadar kolesterol darah pria dan wanita dewasa di Bogor menyatakan bahwa aktivitas fisik berpengaruh nyata terhadap kadar kolesterol darah. Dengan olahraga dapat menurunkan kadar LDL kolesterol dan trigliserida serta meningkatkan kadar HDL kolesterol yang disebabkan karena berkurangnya aktivitas fisik lipase hati yang berfungsi dalam katabolisme HDL kolesterol (Waloya, 2013).

\section{Daftar Pustaka}

Amerika Hearth Association. (2016). American

$$
\begin{aligned}
& \text { Hearth Association Recommendation } \\
& \text { for Physical Activity in Adults. } \\
& \text { https://www.aha/guidesreprts/2016-08- } \\
& \text { 29-aha-chartbook-2016. }
\end{aligned}
$$

Aulia A. (2012). Hubungan Pola Konsumsi Makan, Status Gizi, Stress Kerja dan Faktor Lain dengan Hiperkolesterolemia pada Karyawan PT Semen Padang Tahun 2012. Jakarta: Universitas Indonesia. Gizi Kesehatan Masyarakat. 
Badan Litbangkes. (2013). Riset Kesehatan Dasar (Riskesdas 2013). DEPKES RI Jakarta.

Elon, Y., Polancos, J. (2016). MANFAAT JERUK NIPIS (CITRUS AURANTIFOLIA) DAN OLAHRAGA UNTUK MENURUNKAN KOLESTEROL TOTAL KLIEN DEWASA. Jurnal Skolastik Keperawatan, 1 https://doi.org/10.35974/jsk.v1i2.156.

Fatimah \& Kartini. 2011. Senam Aerobik dan konsumsi zat gizi serta Pengaruhnya terhadap kadar kolesterol total darah wanita. Jurnal Gizi Klinik Indonesia. Vol 8 no 1 Juli 2011:23-27.

Griffin, R. M. (2014). High Cholesterol: What It

Can Do to You. Available at http://www.webmd.com/cholesterol management/features/high-cholesterolrisks-top-2-dangers.

Herawati Isnaini., Mutalazimah et al (2017).

Hubungan Frekuensi Senam Aerobik dan Asupan Kolesterol Terhadap Kadar Martini Santi., Yoentarafa Alodica. (2017).

Pengaruh Pola Makan Terhadap Kadar Kolesterol Total. Jurnal MKMI Volume 13 no 4.

Masi M. N Gresty. (2016). Hubungan Aktivitas Fisik Dan Pola Makan Dengan Perubahan Indeks Massa Tubuh Pada Mahasiswa Semester 2 Program Studi Ilmu Keperwawatan Fakultas
Kolesterol Darah Wanita Usia Subur di Pusat Kebugaran Syariah Agung Fitnes Makamhaji. Jurnal Kesehatan, ISSN 1979-7621. Volume 10 no 2.

Linawati, Sienny. (2012). Perbandingan Marker Inflamasi Antara Sindroma Koroner Akut dan Non Koroner Akut.https://scholar.google.co.id

Lombo, V, R., Purwanto DS ., Masimen , T.V .

(2012). Gambaran Kolesterol Tota Darah Pada Laki-Laki Usia 40-59 tahun Dengan Indeks Massa Tubuh 18,5-22,9. Jurnal Biomedik, 4

Malinti, E., \& Elon, Y. (2019). Hubungan asupan natrium, kalium; indeks masa tubuh, lingkar pinggang dengan tekanan darah pria dewasa muda. Riset Informasi Kesehatan, 8(1), 1-8 doi:10.30644/rik.v8i1.213.

Malik. A.M. (2014). Gambaran Kadar Kolesterol Total Darah Pada Mahasiswa Angkatan 2011 Fakultas Kedokteran Universitas Sam Ratulangi Dengan Indeks Massa Tubuh $18,5-22,9$ $\mathrm{kg} / \mathrm{m} 2$

\section{Kedokteran.e-journal Keperawatan (e-kp) Vol 4 nomor 2.}

Musdalifah., Wicaksono, S., Tien et al (2017).

$\begin{array}{lrr}\text { Hubungan Indeks Massa } & \text { Tubuh } & \\ \text { dengan Kadar Kolesterol } & \text { Total } & \text { pada } \\ \text { Staff dan Guru SMA } & \text { Negeri } & 1 \\ \text { Kendari. } E-I S S N, 4(2), 24430218 . & \end{array}$

Nelson, R. H. (2013). Hyperlipidemia as a Risk Factor for Cardiovascular Disease.Prim 
Care. 2013 March ; 40(1): 195-211. doi:10.1016/j.pop.2012.11.003.

Nugraha Aziz. (2014). Hubungan Indeks Massa Tubuh dengan Kadar Kolesterol Total pada Guru dan Karyawan SMA Muhamadiyah 1 dan 2 Surakarta. eprints.ums.ac.id.

Nurrahmani U. (2012) Stop ! Kolesterol Tinggi. Jogyakarta : Group Relasi Inti Media.

Palmisano B.T., Zhu L., Stafford J.M.(2017). Role of Estrogen In The Regulation Of Liver Lipid Metabolism. Springer International Publishing AG, 227- 256.

Pradono Julianti., Riyadi Hadi., et al (2016). Hubungan Obesitas Sentral Dengan Profil Lipid pada Orang Dewasa umur 26-65 tahun di Kota Bogor. Journal of The Indonesian Nutrition Association. e-ISSN 2528-5874.

Riskesdas. (2013). Riset Kesehatan Dasar. 2013. kesga.kemkes.go.id/images/pedoman/ Data Riskesdas 2013.

Sastradimaja B.Sunaryo., Sukandar et al (2017).

$\begin{array}{llr}\text { Hubungan } & \text { Aktivitas } & \text { Fisik } \\ \text { dengan Kadar } & \text { Kolesterol } & \text { Total } \\ \text { Kolesterol Low } & \text { Density } & \text { Lipoprotein, } \\ \text { dan Kolesterol } & \text { High- } & \text { Density } \\ \text { Lipoprotein pada masyarakat } & \\ \text { Jatinangor. JSK Volume 2 } & \\ \text { nomor 3. }\end{array}$

Rachmayati, S., Sukandar, H., Humaera Zahra. (2014). Korelasi Indeks Massa Tubuh dengan Profil Lipid pada Masyarakat di Jatinangor Tahun 2014. JSK, Volume 3 no 1 .
Rully Batjo, Youla A. Assa et al. (2013).

Gambaran Kadar Kolesterol Low

Density Lipoprotein Darah Pada

Mahasiwa Angkatan 2011 Fakultas

Kedokteran Universitas Sam Ratulangi

Manado Dengan Indeks Massa Tubuh 18,5 - 22,9 $\mathrm{kg} / \mathrm{m}^{2}$. Jurnal e-biomedik hal 843-848.

Sartini., Kardhinata, Harso, E., Amriani. (2015).

Gambaran Obesitas Dan Kadar

Kolesterol Berdasarkan Umur dan Jenis Kelamin pada pasien yang berobat di Rumah Sakit Haji Medan. Jurnal

Biologi Lingkungan. BioLink Vol 2 (1).

Schaefer, E.J. (2010). High Density Lipoprotein ,Dyslipidemia, and Coronary Hearth Disease. Springer Scince Busines Media. USA.

Skinner, Steiner J Mickhael et al (2012)

Cholesterol Curves to Identify Population Norms by Age and Sex in Healthy Weight Children. The 
University of North Carolina at Chapel Hill,

Chapel Hill, NC, USA. https://www.ncbi.nlm.nih.gov/pmc/articles/P MC3368222/pdf.

Sitepu W, Indah. (2014). Hubungan Antara Indeks Massa Tubuh dengan Kadar

Profil Lipid pada pasien dewasa di bagian penyakit dalam Rumah Sakit PHC Surabaya. repository.wima.ac.id.

Suatra. Nugraha Gde I. Ketut. (2018). Hubungan Body Mass Index (BMI) Dengan Kadar Kolesterol Total Darah Pada Populasi Dewasa Di Dusun Tanjung, Kulon Progo, Yogyakarta.

Waloya, Tugul. (2013). Hubungan antara Konsumsi Pangan dan Aktivitas Fisik dengan Kadar Kolesterol Darah Pria dan Wanita.
WHO.(2014). Noncommunicable Diseases (NCD)

Country Profiles. Available at http://www.who.int/nmh/countries/idn_ en.pdf

WHO. (2016). Body Mass Index (BMI)

Classification.

Available

at

https://www.who.int.

Yuliana, Ema. (2016). Hubungan Indeks Massa Tubuh dengan Kadar Kolesterol Total Pada Lansia di Posyandu Lansia " Ngudi Waras" Desa Blulukan Kecamatan Colomadu Karanganyar Jawa Tengah. Fakultas Ilmu Kesehatan. Universitas Muhamadiyah Surakarta. eprints.ums.ac.id. 